psychiatric and other problems, but this option may be less acceptable to patients and doctors. ${ }^{23}$

MIKE PORTER

Lecturer in Medical Sociology DERMOT GORMAN SHHD Research Fellow

University of Edinburgh,

Department of General Practice,

Levinson House, Edinburgh EH8 9DX

1 Grol R, ed. To heal or to harm: the prezention of somatic fixation in general practice. Exeter: Royal College of General Practitioners, 1988.

2 O'Dowd TC. Five years of heartsink patients in general practice. Br Med 7 1988;297:528-30.

3 (icrrard TJ, Riddell JD. Difficult patients: black holes and secrets. Br.Med f 1988;297:530-2.

+ Frecling P, Rao BM, Parkel ES, Sireling LI, Burton RH. Unrecognised depression in general practice. Br. Med F 1985:290:1880-3.

Trlee $A$. Freeling P. Consultation analssis by triggers and sumptoms (CATS). A new objective technique for studving consultations. Fum Pract 1987:4:260-5

6 Pendleton D, Haslar J. Doctor-patien communication. London: Academic Press, 1983.

6 Pendleton D, Haslar J. Doctor-patlent communtcation. London: Academic Press, 1983 . teaching. Oxford: Oxford Medical Publications, 1984.

Maguire $\mathrm{P}$, Fairbairn S. Fletcher C. Consultation skills of voung doctors. 1. Benefits of feedback training in interviewing as students persist. Br.Med f 1986;292:1573-6.
9 Gask L., Goldberg D, Lesser AL, Millar T. Improving the psychiatric skills of the general practice trainee: an evaluation of a group training course. Med Educ 1988;22:132-8.

10 Secretaries of State for Health, Wales, Northern Ireland, and Scotland. Working for patients. London: HMSO, 1989. Cmnd 555.

1 Marinker $M$. Studies of contact behaviour in a general practice. 1. An exposition of methods and a consideration of meanings. $7 R$ Coll Gen Pract 1967;14:59-66.

2 Jenkins $R$, Smeeton $N$, Shepherd $M$. Classification of mental disorder in primary care. Cambridge: Cambridge University Press, 1988. (Psychological Medicine Monograph suppl 12.)

Huvgen FJA. Family medicine, the medical life history of families. Nijmegen: Decker en Van de Vegt, 1978 .

4 Huvgen FJA. Longitudinal studies of family units. FR Coll Gen Pract 1988;38:168-70

15 Collyer JA. Psychosomatic illness in a solo family practice. Psychosomatics 1979;20:762-7.

6 Corney RH. Development and use of a short self-rating instrument to screen for psychosocial disorder. IR Coll Gen Pract 1988;38:263-6.

17 Hunt SM, McEwen J, McKenna SP. Measuring health status. London: Croom Helm, 1986.

8 Goldberg D, Bridges $K$. Screening for psychiatric illness in general practice: the general practitioner versus the screening questionnaire. $f R$ Coll Gen Pract 1987;37:15-8.

19 Goldberg D, Bridges K, Duncan-Jones P, Grayson D. Detecting anxiety and drepression in general medical settings. Br Med f 1988;297:897-9.

20 Wilkinson MJB, Barczak P. Psychiatric screening in general practice: comparison of the general health questionnaire and the hospital anxiety depression scale. $7 R$ Coll Gen Pract 1988:38:311-3.

Cof practice JR Coll Gen Pruct 1987:37:164-7.

22 Zigmond AS, Snaith RP. The hospital anxiety and depression scale. Acta Psychiatr Scand 1983;67:361-70.

23 Fallowfield LJ, Baum M, Maguire GP. Do psychological studies upset patients? fR Soc Med $^{2}$ 1987;80:59.

\title{
Can general practitioners prevent the sudden infant death syndrome?
}

\section{Collaborative epidemiological studies are needed}

Last November the House of Commons social services committee called for urgent steps to improve the paediatric training of general practitioners. Its report noted that fewer than two thirds of new general practitioners had had vocational paediatric training, linking this with a tendency to misdiagnose the early features of ill health in babies who succumb to the sudden infant death syndrome. Cold weather, minor treatable illness, and absent or unemployed fathers were identified as likely factors in unexpected infant deaths, and the report spoke of "worrying questions about the level of awareness among general practitioners of babies at risk."

Yet will improved paediatric training of general practitioners reduce deaths from this syndrome? The assumption underlying the recommendation is that we understand the course of the syndrome sufficiently well to allow general practitioners and health visitors to recognise early those children who are likely to succumb. Yet the truth is not nearly so clear cut as the committee was led to believe, and unfortunately, the committee failed to take evidence from general practitioners. The frequency of presentation of illness in general practice in the first year of life is extremely high: in one inner city population over four fifths of children were seen with one or more episodes of respiratory illness in the first year of life. ${ }^{2}$ Only a small fraction of these children was referred to a specialist.

Studies from a hospital specialist's perspective may unfortunately reach conclusions about community care that are not borne out in reality. For example, in 1978 a preliminary report of the Department of Health's multicentre study of postneonatal morbidity found that 18 features were common in infants who had died suddenly and unexpectedly. ${ }^{3}$ The report suggested that several "major symptoms" might be markers of life threatening illness and would thus alert general practitioners to this possibility. These features were nonspecific-for example, unusual drowsiness, irritability, an altered cry, being off feeds, or excessive crying.

Subsequent studies testing the predictive value of such a classification showed that these major symptoms were too common in children seen by general practitioners to be predictors of a particular outcome. ${ }^{+5}$ Furthermore, inquiries of parents showed a wide variation about what they termed "irritable," "altered cry," or "diarrhoea." Professionals were also likely to differ in interpreting such terms, a feature that added to the difficulty of using symptoms to assess the seriousness of a case.

About one in every 500 births results in the sudden infant death syndrome. Thus for general practitioners the event is rare, occurring once or twice during a professional lifetime. The diagnosis depends on the thoroughness of the necropsy: the more detailed the investigations the less likely are deaths to fall into this unsatisfactory category.

Given this confusion, what can general practitioners do? They can be aware of those groups of children in their practices who are most vulnerable to the sudden infant death syndrome and ensure that primary care is available. Intensive support by health visitors of families identified as being possibly at risk may also be valuable,${ }^{6}$ but this remains to be confirmed by a randomised controlled trial.

Faced with a baby from a vulnerable group with features associated with the syndrome a general practitioner can arrange either for an intensive review by himself or herself or another member of the primary care team or for admission to hospital. In a deprived area, however, many babies may fall into this category and the resource implications of intensive management or admission may be considerable, possibly resulting in detriment to the quality of care for the remainder of the practice. General practitioners are constantly balancing the investment of time and resources against the likely returns. Without any method of more precisely targeting the efforts of doctors or even knowing whether they are beneficial in preventing a rare event the recommendation of any clear strategy for preventing the sudden infant death syndrome in individual subjects is unlikely.

What we need is more community based research entailing collaboration among general practitioners, epidemiologists, and paediatricians. This should develop a reliable classification of illness, particularly respiratory illness, which might be used as the basis of studies of prognosis in general practice. Such studies might allow general practitioners to identify vulnerable children more precisely and allow 
randomised controlled trials of alternative management strategies to be mounted. The understanding gained from these studies could then form the basis of improved paediatric training of general practitioners.

C J WATKINS

General Practitioner,

Backwell,

Bristol BS19 3HA
Social Services Committec. Perinatal, neomatal and infant mortality. London: HMSO, 1988. (HC 54 .)

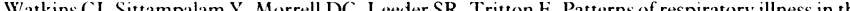
first vear of life Br.Med7 1986:293:794

3 Stanton AN, Downham MAPS, Oaklev JR, Emery JL, Knowelden J. Terminal symptoms in children dving suddenly and unexpectedly at home: preliminary report of the DHSS multicentre children dying suddenly and unexpectedly at home: prehm

4 Wilson AD, Downham MAPS, Forster DP. Acute illness in infants; a general practice study. $f R$ Coll Gen Pract 1984;34:155-9.

5 Wright A, Luffingham GH, North D. Prospective study of symptoms and signs in acutely ill infants in general practice. $\mathrm{Br}$ Med $\mathrm{f} 1989 ; 294: 1661-2$.

6 Carpenter RG, Gardner A, Jepsom M, et al. Prevention of unexpected infant death. Evaluation of the first seven years of the Sheffield Intervention Programme. Lancet 1983;i:723-7.

\section{National variations in medical practice}

\section{Culture influences medicine more than science does}

Many doctors like to bask in the reflected glory of medicine as a scientific undertaking that transcends international barriers. Indeed, this is what medical students are largely taught. In so far as cultural factors are admitted to play a part it is as quaint throwbacks to a prescientific era that is steadily disappearing. Now Lynn Payer, a basic scientist turned journalist, has had the bright idea of subjecting to close scrutiny the values and practices of medicine in four highly developed countries with equivalent life expectancies (the United States, West Germany, France, and Britain), and she concludes that many diagnoses are more influenced by national characters, cultures, and philosophies than by scientific considerations. ' Her book will come as a revelation to many doctors because they do not read much about each other's work let alone about cultural oddities. Few doctors in Britain are able to name a single French medical journal, doctors in France rarely read outside their own journals, and a vice president of the American Cancer Society, when told in the mid-1970s of a study testifying to the efficacy of lumpectomy in breast cancer published in the $B M \mathcal{F}$, replied, "We don't read much foreign literature here."

So we remain ignorant of commonly diagnosed diseases that just don't travel. Take the French disease spasmophilia. It is a condition that increased sevenfold in the 1970s and is diagnosed on the basis of an abnormal Chvostek's sign and oddities on an electromyogram. In the United States if it exists at all it is as panic disorder. In Britain it does not exist - so presumably sufferers in France might be cured simply by crossing the English Channel. West Germans are prone to Herzinsuffizienz, a condition approximating to cardiac insufficiency and accounting at least in part for why on average Germans consume six times as many heart drugs as their British counterparts and why cardiac glycosides are the second most prescribed group of drugs after non-narcotic analgesics. Being romantic people, the Germans regard the heart not as a mechanical pump but as an organ with a life of its own; they thus have low rates of bypass surgery but are fond of subjecting the heart to examination by electrocardiography. One survey of supposedly healthy citizens of Hamburg showed a rate of abnormalities of $40 \%$. So much for science.

Germans also : yard low blood pressure as a malaise demanding attention. No fewer than 85 drugs are listed for its treatment, and annual consultation rates are 163 for every million people. Hardly anyone in Britain is treated for low blood pressure. Doctors in the United States think that treating low blood pressure amounts almost to malpractice, whereas many German doctors regard an untreated diastolic pressure of $70 \mathrm{~mm} \mathrm{Hg}$ with horror.

Payer argues that there are philosophical explanations for these discrepancies. German romanticism is blamed for German medicine's cardiac preoccupations. American medicine's aggressiveness and military analogies - the war against cancer, the body as a battlefield-owe much to that country's culture and little to science. The French emphasis on aesthetics goes a long way to explain the 10 free physical treatment sessions provided to get into shape after childbirth. Cultural values, too, presumably explain why in the United States so many women want their breasts surgically enlarged whereas in France equivalent numbers want theirs reduced.

And British medicine, how does it fare? Lynn Payer's overwhelming impression is of a practice impregnated by scepticism, cynicism, and conservatism. Whereas in America it is better to do something than nothing, in Britain medicine is cautious about making matters worse. The British have a higher threshold for disease, do less of virtually everything (from hysterectomies to appendicectomies), and spend far less money. Not for nothing, apparently, are British doctors regarded as the accountants of the medical world.

Medicine and Culture should certainly be read by medical students for it would help explain why the real world they encounter when they qualify is often so different from what is portrayed in the textbooks. Their seniors should read it too, but I doubt that they will-and even if they do they won't much like it. They will dub it anecdotal and unscientific in contrast to their own clinical practice and professional theories. In so doing they will be, as ever, faithful to their culture.

Clinical Professor of Psychiatry,

ANTHONY CLARE

Trinity College,

Dublin 2

1 Payer L. Medicine and culture. I'arieties of treatment in the United States, England, West (Germany, and France. New York: Henry Holt and Company, 1988. 